\title{
O efeito de padronização de corpos, dietas e regimes pelo discurso médico:
}

\author{
alimentação nas enciclopédias
}

\section{The effect of standardizing bodies, diets and regimes by medical discourse:}

alimentation in encyclopedias

\section{Phellipe Marcel da Silva Esteves ${ }^{1}$}

RESUMO: Neste artigo, tomaremos como material de análise enciclopédias publicadas no Brasil de 1958 a 1973, procurando investigar, de modo geral, de que maneira os sentidos sobre comida e alimentação circulam em meados do século $X X$ nesses instrumentos, e, especificamente, quais as relações entre comida, alimentação, corpo, gênero e sujeito na fase de publicação das enciclopédias investigadas, quando elas se multiplicam e se popularizam no sistema editorial brasileiro.

Palavras-chave: alimentação; enciclopédias; análise do discurso.
Abstract: This article aims to analize encyclopedias published in Brazil between 1958 and 1973, in order to investigate how the meanings of food circulate in the middle twentieth century in these instruments, and, more specifically, the relations between food, alimentation, body, gender and subject at that period, when the publication of encyclopedias multiply and popularize in Brazilian publishing system.

Keywords: alimentation; encyclopedias; discourse analysis.

\footnotetext{
1. Professor adjunto do Setor de Linguística da Universidade Federal Fluminense, onde também concluiu seu doutorado. Formado em Comunicação Social (Jornalismo) pela UFR] e com mestrado em Letras (Língua Portuguesa) pela Uerj, sempre se interessou por investigar questões relativas à alimentação e à comida duma perspectiva materialista. Em 2017, publicou o livro Discurso sobre alimentação nas enciclopédias do Brasil: Império e Primeira República, pela Eduff, decorrente de sua tese de doutorado. Em breve, lançará um volume acerca da história das enciclopédias no Brasil, intitulado Desejo de enciclopédia: o saber total, resultado de uma residência de pesquisa na Fundação Biblioteca Nacional (PNAP-R) e ganhador de fomento para editoração da Faperj (APQ3).
} 
"A gente não quer só comida."

[Só comida?]

(Titãs, e nossa resposta ao verso)

\section{Letras iniciais}

Com a expansão da publicação das enciclopédias no Brasil, ocorrida entre as décadas de 1950 e 1970, as obras de referência passam a circular e ocupar um lugar ainda mais importante na produção de efeitos de sentido sobre aquilo que vai sendo dito (sobre o) brasileiro e a comida e alimentação (brasileiras). ${ }^{1}$ As enciclopédias participam consistentemente de um projeto de formação de leitor no Brasil, permitindo-Ihe conhecer aquilo que deve ser sabido para ser brasileiro. Nas próximas páginas, pretendemos responder a questões fundamentais para entendermos como os saberes culinários, gastronômicos, nutricionais etc. dominantes circulam na sociedade, guiandonos por análises de materialidades das seguintes enciclopédias:

a) Enciclopédia brasileira de Alarico Silveira² ${ }^{2}$ lançada em 1958 pelo Instituto Nacional do Livro, a primeira enciclopédia publicada no Brasil a ser acompanhada, em seu título, do gentílico "brasileira";

b) Enciclopédia Barsa ${ }^{3}$, de 1964, que passa a ser a enciclopédia mais vendida no Brasil;

c) Enciclopédia da mulher ${ }^{4}$ de 1973, uma das primeiras enciclopédias da Editora Abril e provavelmente uma das primeiras enciclopédias brasileiras não especializadas em comida e alimentação a incluir receitas em suas páginas. ${ }^{5}$

\section{A condição brasileira impressa}

No período de 1958 aos anos 1970, há uma dominância de um discurso que trata do nacional e do brasileiro, presente inclusive nos títulos dos instrumentos:

1 É a partir da década de 1960 que o número de enciclopédias publicadas no Brasil deslancha. As políticas de alfabetização também são motivo para uma expansão do mercado editorial. De acordo com dados do IBCE (<http://seriesestatisticas.ibge.gov.br/series. aspx?vcodigo=CD101\&t=taxa-analfabetismo-pessoas-15-anos-mais $>$; acesso em jan. 2019), entre sujeitos de 15 a 19 anos, a taxa de analfabetismo era de $24,3 \%$, enquanto que, entre sujeitos de 50 anos ou mais, a taxa chegava ao dobro, $48,4 \%$. A publicação de enciclopédias se inscreve nessas condições de produção sócio-históricas: com um público leitor em expansão, já é possível que se lancem mais títulos.

2 INL. Enciclopédia brasileira de Alarico Silveira: Edição patrocinada pela Fundação Edmundo Bittencourt. Rio de Janeiro: Ministério da Educação e Cultura, Instituto Nacional do Livro [INL], 1958.

3 ENCYCLOPADIA BRITANNICA EDITORES. Enciclopédia Barsa: elaborada sob a supervisão dos editôres da Encyclopædia Britannica. Rio de Janeiro/São Paulo: Encyclopædia Britannica Editores, 1964.

4 ABRIL CULTURAL. Enciclopédia da mulher. 2. ed. São Paulo: Abril Cultural, 1976 [1973]

$5 \quad$ No levantamento feito por Pereira (2005), nota-se que a Enciclopédia da mulher é a quarta enciclopédia publicada pela Abril Cultural (considerando-se como enciclopédia, nesse caso, títulos que se iniciam por essa palavra, embora saibamos que esse recorte é extremamente redutor), tendo sido antecedida pela Enciclopédia da agricultura (1967), pela Enciclopédia Abril (1971) e pela Enciclopédia Disney (1972). Interessamonos, entretanto, pela Enciclopédia da mulher por muitos outros motivos que se desdobrarão à frente. 
A Enciclopédia Brasileira Mérito ${ }^{6}$, publicada em 1959 pela editora Mérito em São Paulo, Rio de Janeiro, Porto Alegre e Recife, é a primeira enciclopédia concluída a se apresentar como brasileira. Retomando a combinação de dicionário e enciclopédia (na filiação ao Larousse Universal, 1865-76) e as partes dedicadas à geografia e à fauna e flora, a enciclopédia traz definições concisas. Vemos aí não mais a memória colonialista, mas a unidade nacional e a relação com outras tradições enciclopédias acionadas para a constituição da enciclopédia brasileira. (Nunes, 2012, p. 2)

Um projeto de Enciclopédia brasileira de Mário de Andrade (Andrade, 1993) nunca chega a ser concluído tal qual planejado por esse antigo servidor do Instituto Nacional do Livro, mas a enciclopédia que leva o nome do ex-ministro do Supremo Tribunal Federal de Cetúlio Vargas, Alarico Silveira, ${ }^{7}$ começa, em 1958, a ser publicada pelo mesmo instituto, nunca saindo do primeiro volume. ${ }^{8}$ Um ano depois, como podemos ler na citação anterior de Nunes (2012), também é publicada uma outra enciclopédia que leva o gentílico "brasileiro" em seu título: a Enciclopédia brasileira Mérito," produzida pela editora homônima em três regiões brasileiras, Sul, Sudeste e Nordeste.

Se nunca antes no Brasil uma enciclopédia havia incluído o adjetivo pátrio em seu título, é sintomático da construção de uma imagem de Brasil e de brasileiro que, em apenas dois anos, dois instrumentos o tenham feito - apesar de somente um deles ter sido concluído. É também interessante que as iniciativas tenham partido uma do âmbito público (EBAS) e uma do privado (EBM). Podemos afirmar que o final dos anos 1950, durante a Cuerra Fria e o governo Juscelino Kubitschek, é momento de afirmação e legitimação da condição brasileira, da brasilidade, do elencar das coisas, histórias, ciências, técnicas do Brasil. Essa publicação praticamente concomitante de duas Enciclopédias brasileiras acarreta uma disputa de sentidos não apenas de como designar o sujeito, mas também do que dizer sobre o brasileiro: o que, no Brasil, vale entrazr numa enciclopédia, como deve ser dito, o que deve ser recenseado ou censurado? Isso passa a ser uma inquietação constante dos discursos das enciclopédias.

A primeira enciclopédia já editada por um órgão do governo federal do Brasil, a Enciclopédia brasileira de Alarico Silveira é dita como a continuidade do projeto de Alarico Silveira, através de suas fichas colecionadas ao longo de décadas, com impressões sobre as coisas do Brasil. Filiando-se a um imaginário de constituição de povo, região e sentimento nacionais, essa enciclopédia possui marcas gramaticais que vão se repetindo ao longo dos verbetes, desde a apresentação de Américo Jacobina

\footnotetext{
6 MÉRITO. Enciclopédia brasileira Mérito. São Paulo: Editora Mérito, 1958.

7 Doravante EBAS.

8 Na "Introdução" da publicação em livro do projeto de Mário de Andrade, a organizadora retoma a visita do escritor à casa de Alarico Silveira, que já planejava a escrita de uma enciclopédia brasileira, contemporaneamente, quando vivo: "Como se sabe, este projeto do Instituto Nacional do Livro não progrediu da forma esperada. Talvez iniciando a execução do plano, ou simplesmente por causa da recomendação de Augusto Meyer, Mário de Andrade vai, em companhia de José Bento de Faria Ferraz, seu secretário em São Paulo, à casa de Alarico Silveira, que já colecionava material para uma edição do gênero. De fato, o tomo I da Enciclopédia Brasileira de Alarico Silveira sai em 1958, mas em nada se assemelha ao modelo proposto ao INL" (Toni, 1993, p. XXII). 
Lacombe, o então diretor da Casa de Rui Barbosa. O uso da primeira pessoa do plural, na figura de pronomes pessoais ou possessivos, é constante: "nossa história" e "nossas coisas" comparecem nos elementos pré-textuais e textuais.

Não se consegue encontrar um verbete relativo à "comida" ou à "alimentação" na Enciclopédia brasileira de Alarico Silveira, que parte da letra A e chega ao verbete Anzol-de-tenda. Como ela não passou do primeiro volume, a EBAS, que não apresenta nem o verbete "comida" (por um impedimento da própria organização alfabética: como o volume só chegou a "Anzol-de-tenda", era impossível chegar a verbetes iniciados pela letra C) nem "alimentação", é considerada aqui como um marco desse efeito explícito de brasilidade nas enciclopédias. ${ }^{10}$ Ela funda a discursividade das enciclopédias ditas brasileiras em seus títulos e publicadas no Brasil, mas não da comida e da alimentação brasileiras. Esse papel é cumprido por outras obras.

Seis anos depois da publicação da EBAS, é publicada a Enciclopédia Barsa, cujo título remete à união de duas famílias em casamento: Dorita Barrett de Sá e Alfredo Almeida de Sá. A empresa familiar é responsável por distribuir os produtos da empresa Encyclopaedia Britannica no Brasil-por si só, o nome da empresa é uma contradição produtiva -e, ao final da década de 1950, resolve verter o instrumento europeu para o público brasileiro, mas acabou sendo decidido que a edição brasileira não seria uma tradução ou adaptação da inglesa: a redação da Enciclopédia Barsa (doravante EB) é completamente feita por "brasileiros ou por pessoas intimamente vinculadas ao Brasil", conforme lemos no prólogo de Antônio Callado (Callado, 1964, Prólogo, p. 1), convidado a chefiar a redação da obra em 1960, lá ficando empregado até 1963, logo antes de sua publicação. Apesar de não ser intitulada como Enciclopédia brasileira, ousamos aqui uma interpretação: o nome próprio Barsa, tendo sido formado como um acrônimo de Barret + Sá, também é uma recombinação de Brasa, que ressoa Brasil, paronimicamente. Evidentemente, não se trata de uma leitura obrigatória, mas de um efeito possível: a Barsa, a enciclopédia mais vendida no Brasil por décadas, funciona como a referência das obras de referência. Uma enciclopédia brasileira não em título, mas simbolicamente.

Em 1973, é lançada a Enciclopédia da mulher (daqui em diante, EM) pela editora Abril Cultural, da família Civita - proprietária também das revistas Veja e Cláudia -, a primeira enciclopédia não alfabética e não específica sobre comida, gastronomia, culinária e alimentação publicada no Brasil a reservar uma seção específica chamada "cozinha", lá publicando receitas, e também a primeira enciclopédia brasileira publicada pela Abril. Essa obra, à cuja segunda edição, de1976, tivemosacesso, foi publicada no Brasil e aparentemente não é traduzida ou adaptada de outros volumes editados

\footnotetext{
10

Até um momento anterior da análise, ainda assim tentávamos entender como os sentidos sobre comida e alimentação circulavam no instrumento linguístico, tomando como recorte verbetes sobre gêneros alimentícios que íamos reconhecendo na leitura. Concluímos posteriormente que esse procedimento, entretanto, era falho: se o que buscamos são as regularidades e as rupturas no discurso sobre comida e alimentação e se nosso critério desde o início da pesquisa era justamente buscar verbetes que, de uma maneira ou de outra, se relacionassem textualmente a esses substantivos, utilizar como material de análise, por exemplo, os verbetes "abacate", "alho" e "alfavaca", sem mesmo que eles tivessem sido indicados num índice remissivo, de modo hipertextual, não seria uma maneira precisa de trabalhar. Esse procedimento poderia levar a uma análise inacurada, além de tudo, por eu, sujeito pesquisador, sem perceber pular algum verbete que eu nem mesmo desconfiasse evocar sentidos sobre comida e alimentação.
} 
no estrangeiro (ao menos não há referência a isso, o que também não indica certeza), diferentemente da Enciclopédia da mulher e da família, de 1971. ${ }^{11}$ Em cada volume da enciclopédia há seções que se repetem tematicamente, junto a subtemas. Na apresentação à segunda edição da $E M$, assinada por Victor Civita, é o campo lexical de "Brasil" que vai provocando o efeito de brasilidade (embora se faça uso de primeira pessoa do plural, que vai construindo a imagem da equipe editorial da $E M$ ):

\begin{abstract}
$E M_{1}$ : Leitora amiga:
Em outubro de 1961, a ABRIL lançou o primeiro número de uma revista dedicada ao público feminino. Seu nome: CLAUDIA. Na ocasião, dissemos que ela havia sido criada para tornar-se a melhor amiga de todas as brasileiras modernas e inteligentes. $O$ tempo e nossas leitoras incumbiram-se de mostrar que tínhamos razão. Hoje, CLAUDIA é a mais importante revista feminina do país.

Aproveitando a grande experiência de CLAUDIA e atendendo ao crescente desejo de atualização das brasileiras, estamos relançando esta ENCICLOPÉDIA DA MULHER. A coleção propõe-se oferecer às leitoras tudo o que elas precisam conhecer sobre o seu papel na sociedade e o seu pequeno-grande mundo: o lar. Vamos ajudá-las na educação e na saúde da família; torná-las mais belas e elegantes; atualizá-las com o tempo em que vivemos; ensiná-las a economizar; resolver dúvidas quanto a seus direitos na sociedade; sugerir soluções para problemas de decoração e construção. Enfim, enriquecer seu mundo com informações atuais e abundantes.

Estamos certos de que a ENCICLOPÉDIA DA MULHER irá tornar-se permanente fonte de consultas e nos alegramos sabendo que, com isso, atingimos plenamente nosso objetivo: ajudar a mulher brasileira a viver melhor.

Cordialmente,

Victor Civita. ${ }^{12}$
\end{abstract}

Adjetivar e/ou designar por meio de gentílicos, assim como repetir itens lexicais como "nacional", "nação", "país", "Brasil", é constituir um espaço de que se discursiviza, para quem se discursiviza e sobre o qual se discursiviza. No caso da EM, trata-se de uma enciclopédia que produz como leitor inscrito imaginário "todas as brasileiras modernas e inteligentes", com o efeito de sentido de enriquecer e fazer saber tudo que elas precisam sobre seu "pequeno-grande mundo: o lar".

Aimagem de objetivo nela produzida é "ajudar a mulher brasileira a vivermelhor". Esse efeito de completude e totalidade do universo da mulher - "oferecer às leitoras tudo o que elas precisam conhecer sobre o seu papel na sociedade e o seu pequeno-grande mundo" - faz parte do próprio funcionamento das enciclopédias. No que tange a uma enciclopédia cujo público-alvo é inscrito numa formação imaginária (Pêcheux, 1990 [1969]) que significa as mulheres como donas de casa, as temáticas serão todas voltadas ao aprendizado das coisas do Brasil que elas imaginariamente precisam saber.

Um outro ponto a ser lembrado é que não existe uma Enciclopédia do homem, nem antes nem depois da publicação da Abril, mas, como já antecipamos, na mesma década de 1970 é publicada a Enciclopédia da mulher e da família (1971). Duas enciclopédias com a locução adjetiva "da mulher" no

11 Uma enciclopédia da editora Delta traduzida do francês, cujo primeiro volume discursiviza sobre comida brasileira numa receita de “Coisas do mar do Brasil”. DELTA. Enciclopédia da mulhere da família. Rio de Janeiro: Editora Delta, 1971. 
título, com uma diferença de dois anos entre suas respectivas publicações. Uma injunção a separar os conhecimentos entre homem e mulher, mas que produz também outros efeitos: uma Enciclopédia da mulherse oporia a uma Enciclopédia do homem. Não existindo esta última, nossa hipótese é a de que, ao se autopredicar "da mulher", a enciclopédia se opõe a enciclopédias sem adjuntos adnominais relativos a sexo: todas as outras enciclopédias seriam produzidas como do homem, visto que os saberes lá circulantes são significados como dele, e não da mulher. ${ }^{13}$ Não é necessário dizer para ser significado.

Intensifica-se, pelo discurso circulante na EM já a partir de seu título, um efeito de dualismo presente na constituição dos sentidos sobre comida e alimentação: o de que o espaço da cozinha é exclusivo da mulher, e que a entrada de um homem lá é algo como uma invasão, uma incursão que precisa de autorização no discurso, materializada pela menção de que dada presença na cozinha é masculina, uma excepcionalidade diante da obrigatoriedade de a mulher ocupar esse espaço. No outro polo do efeito de dualismo produz-se a imagem de sujeito masculino como lugar social em que se produz, circula e a quem se oferta o conhecimento: a entrada da mulher no campo do conhecimento é também discursivizada como uma excepcionalidade, daí um título como Enciclopédia da mulher. Quando o público-alvo imaginário, o leitor inscrito, precisa comparecer no título sem que haja contraste com títulos antônimos ou com relação de sentido afastada, isso pode ser interpretado como da ordem da necessidade.

As imagens de leitor, do conhecimento e mesmo de Brasil, embora se toquem, são distintas na Enciclopédia Barsa (1964) e na Enciclopédia da mulher (1973): na primeira, empreendese uma construção de um leitor brasileiro, e não se discursiviza sobre seu gênero (embora, como já afirmamos, o silêncio possa, nesse caso, significar justamente que o leitor inscrito é o sujeito homem). Na segunda, fala-se da brasileira, e o gesto de leitura sobre a mulher demarca uma interpretação sobre a comida e a alimentação que não são as mesmas: na $E B$, diz-se da comida num discurso que, diferentemente do que se produz na $E M$, se projeta sem receitas, sem recomendações. Dois processos discursivos distintos na produção de sentidos.

Na falta de sequências da EBAS para nosso trabalho - usada aqui como marco histórico dessa fundação da discursividade enciclopédica brasileira-, mais à frente apresentaremos as análises das sequências discursivas sobre comida e alimentação da $E B$ e da $E M$. Na $E B$, procedemos ao recorte do verbete "Alimento" - não havia verbete "Comida" no instrumento-, mostrando como a enciclopédia define os alimentos. A EB apresenta como subverbetes ou intertítulos de "Alimentos": "Alimentos Protéicos", "Hidratos de Carbono", "Corduras", "Sais Minerais", "Vitaminas", “Água”, "Valôres de Certos

13 E embora não haja nem antes nem depois da Enciclopédia da mulher uma "do homem", mais recentemente, no século XXI, vemos a propagação de alguns títulos de obras de referência - como livros de culinária - e programas de cozinha materializando o substantivo "homem" em seu título: dois exemplos que podemos dar são o livro Senhor prendado: um homem que se diverte na cozinha (Aguiar, 2011) e o programa de TV Homens na cozinha/Homens gourmet (do canal Bem Simples/Fox Life, que trocou o nome do programa, de 2013 para 2014, mas que, nas chamadas comerciais, ainda o anuncia pelo nome original). É produtivo pensar que, em contraste, assim como não há uma Enciclopédia do homem, também não há um livro chamado Senhora prendada - nunca houve nem mesmo um livro já publicado no Brasil com o adjetivo "prendada" em seu título fazendo referência, no subtítulo, à diversão feminina na cozinha, ou um programa de TV designado Mulheres gourmet. 
Alimentos", "Conservação de alimentos", "Regime que Satisfaz as Necessidades do Organismo", "Ceografia da Alimentação", "Áreas Alimentares", "A Alimentação no Brasil", "Adulteração de Alimentos". Excluímos alguns desses para nos concentrarmos em nosso objeto, as relações entre discurso sobre a alimentação e a constituição do sujeito (brasileiro, associado também, em seu silêncio, à masculinidade).

Já na $E M$, que não é dividida em verbetes, mas em artigos e seções mapeados em sumários e índices ao início ou ao final dos volumes, recorremos a estes últimos elementos pós-textuais e, daí, à seção "Cozinha". Selecionamos os artigos cujos títulos dissessem de uma relação entre comida, alimentação, Brasil, brasileiro. Ao começo de nossa leitura da EM, chegamos às seguintes entradas nos índices e sumários dos sete volumes da enciclopédia: feijão, aguardente, miúdos e vísceras, castanhas, coco, linguiças, maracujá, tangerina e frutas do Norte e Nordeste. Predicam-se alguns como "bem brasileiros" ou "brasileiríssimos", outros como "tipicamente brasileiros", mas também recolhemos artigos, como o sobre tangerinas, que afirma que a planta é "cultivada praticamente em todo o Brasil".

Esse procedimento analítico nos auxiliou a perceber que o espaço (do sujeito) brasileiro vai sendo significado ora como lugar de consumo e apreciação de produtos ditos brasileiros, ora como um tópos de cultivo e exploração agropecuária. Ademais, é relevante dizer que praticamente todos os volumes da EM incluem algum artigo, na seção "Cozinha", falando sobre gêneros brasileiros, do Brasil, cultivados no Brasil: é um ritual de discursivização sobre o nacional que se destaca diante das outras enciclopédias que temos visto. O modo de introduzir, designando, o discurso sobre comida e alimentação nas duas enciclopédias em tela já interessa do ponto de vista da filiação ideológica. Fala-se da casa, fala-se biologicamente de algo. Cozinha x espécie.

\section{Corpos, gêneros, dietas e regimes}

Tanto EB quanto EM significam o alimento e a comida em alguns subverbetes e artigos, inscrevendo-se numa Formação Discursiva (doravante FD; Pêcheux, 2009 [1975]) médica. Já no início do verbete "Alimento", da EB, isso pode ser conferido:

$\mathrm{EB}_{4}{ }^{14}$ ALIMENTO. Tôdas as formas de vida, tanto vegetais quanto animais, necessitam de alimentos em certas quantidades e proporções mínimas para assegurar sua vida e reprodução. Apesar da grande diversidade das coisas vivas, pode-se dizer que têm, cada uma, duas necessidades alimentares essenciais: (1) compostos que são fontes de energia e (2) substâncias cuja finalidade principal é preencher necessidades estruturais ou funcionais. Muitos alimentos atendem a ambas as necessidades e, em muitos casos, o que é necessidade dietética para uma espécie, nenhuma utilidade tem para outra, capaz de sintetizar o mesmo alimento de fonte material diversa..$^{15}$

14 Este artigo se inscreve num trabalho mais amplo, uma continuação de nossa pesquisa de doutorado. Por isso mantivemos a notação e a numeração originais. 
Fala-se dos alimentos englobando todas as espécies, polarizando-as em animais e vegetais de maneira a separá-las e voltando a reuni-las sob o rótulo de "coisas vivas". Produz-se o efeito de que as "necessidades alimentares essenciais" poderiam ser divididas em dois grupos, introduzidos por dois nomes que se inscrevem numa posição discursiva (Pêcheux, 2009 [1975]) ancorada na bioquímica, ainda na FD médica: "compostos" e "substâncias". Uma ou outra, na sequência acima, provoca o efeito de completarem o organismo com algo que lhe falta, seja uma carência de energia, seja estrutural ou funcional. Essas necessidades são qualificadas com o adjetivo "dietética": "o que é necessidade dietética para uma espécie, nenhuma utilidade tem para outra". Produz-se o efeito de que, entre as espécies, há certa variedade nas necessidades alimentares. No entanto, o mesmo não é dito para uma mesma espécie, como a humana. Ao utilizar os sintagmas nominais "necessidade dietética" e "utilidade" em relação anafórica, a EB significa a dietética também segundo um discurso médico utilitário. Uma biologização da alimentação humana, que é significada em termos de uniformidade. Nada haveria abaixo da espécie. Mais à frente, no mesmo verbete, diz-se da alimentação das "formas mais complexas de vida", em que se disserta sobre os "homens":

EB $_{5}$ : ALIMENTO. [...] A alimentação das formas mais complexas de vida, animais superiores e homens, difere da das plantas e microrganismos em aspectos importantes. Primeiro, homens e animais superiores precisam de uma série de compostos orgânicos, sem os quais não sobrevivem. Segundo, precisam atender não apenas as necessidades das diversas células, como a de tecidos complicados. Terceiro, dependem das plantas e microrganismos para satisfazer suas dietas. Quarto, necessitam mais calorias, a fim de suprir a energia gasta pela atividade muscular. ${ }^{16}$

A alimentação do homem é dita como semelhante à de "animais superiores", sem especificidades. No recorte "homens e animais superiores precisam de uma série de compostos orgânicos, sem os quais não sobrevivem", pudemos perceber que há uma regularidade: itens lexicais como "necessitar", "precisar" e semelhantes se repetem quando se trata da alimentação, e, às vezes acompanhados, provocando o efeito de que a vida humana depende disso - "[...] sem os quais não sobrevivem". São dominantes os sentidos de uma biologização da comida e da alimentação, como necessidades de sobrevivência, vitais.

A inscrição dos efeitos de sentido sobre alimento nas posições discursivas da dietética e da nutrologia - que se colam no interior do discurso médico - significa conforme um "discurso que centra a conservação da boa saúde e a cura das enfermidades em torno da obediência de uma "dieta" que, etimologicamente, constitui todo um estilo de vida, todo um modo de relacionar-se com o cosmos" (Ory, 2009 [2006], p. 162). Essas posições funcionam em continuidade às posições higienista e fisiológica que vimos em enciclopédias do século XIX e também nas do início do século XX (Esteves, 2017). As posições da nutrologia e da dietética moderna interpretam e produzem sentidos em contato, concordância e praticamente sem conflitos com a fisiologia e com a higiene. Uma das diferenças é que essas posições mais dominantes no século XIX produziam efeitos de coletividade. A dietética nascida no século XX, diferentemente, é um discurso que se projeta ao indivíduo: medicina individual, não social: 
Nasce então a dietética moderna no seio do sistema estabelecido, a partir de um discurso novo sobre as "vitaminas" (na Suíça, em torno do Doutor Bircher-Brenner). O movimento já se acha bem individualizado em terreno anglo-saxão no período entre-guerras, em uma perspectiva de racionalidade nutricional. [...] o movimento ganhou ainda maiores dimensões nos países ocidentais, dado que havia a esta altura surgido uma nova profissão, a de dieteticista - ou melhor, de médica dieteticista, dado que a profissão foi inicialmente de maioria feminina, e assim continuou sendo. [...] Na geração seguinte, a competência dietética vai penetrar ainda um pouco mais no coração das práticas sociais, suscitando duas estratégias de implantação, a dos médicos formados nessa nova especialidade "nutricionistas", e a das primeiras dieteticistas como profissionais liberais. (Ory, 2009 [2006], pp. 162-163)

Ory recupera a história das médicas dieteticistas como maioria entre profissionais que seguiam nessa área. Essa divisão de gêneros reverbera também na imagem projetada de quem são os sujeitos que frequentam e/ou precisam de especialistas em dietas e, discursivamente, no suposto público leitor de um discurso inscrito na posição dietética. A relação é dialética: efeito de que a dietética se supõe um lugar ocupado predominantemente por sujeitos mulheres e de que os sujeitos mulheres supõem precisar da dietética. Circula o efeito de sentido de que a alimentação de acordo com uma dieta específica é acorde com a ciência, é razoável e melhor para o ser humano e, mais especificamente, para a mulher. Esse discurso regula também aquilo que é boa ou má alimentação. $\mathrm{Na} \mathrm{EB}_{12}$, diz-se:

$\mathrm{EB}_{12}$ [extrato]: Josué de Castro, em sua Ceografia da Fome, considerou a Amazônia e largos trechos do litoral setentrional e oriental como áreas de fome endêmica; o sertão semi-árido, como área de epidemias de fome; e o restante do país, como áreas de subnutrição, por adotar regimes alimentares inadequados. ${ }^{17}$

Projetam-se, sobre o objeto discursivo região geográfica, efeitos de sentido orgânicos: por meio de um discurso legitimador da FD médica, materializado no nome do médico Josué de Castro e de uma de suas obras mais famosas, publicada em 1946, a Geografia da fome, as regiões brasileiras vão sendo significadas como mais ou menos saudáveis. Uma correlação entre biologia e geografia. Josué de Castro também ocupava outros lugares sociais no Brasil da primeira metade do século XX, como o de geógrafo e o de nutrólogo. Essa incursão e entrecruzamento por posições discursivas afetadas por distintas disciplinas (a nutrologia, a medicina, a geografia, a geopolítica) produz um efeito de legitimidade: fala-se de geografia, de medicina, de nutrição, de fome, ao mesmo tempo, recobertos por um discurso científico que legitima as posições. Circulam sentidos de que no Brasil a fome se dá em todas as regiões, com características e motivos vários.

Nessa sequência só há a presença de uma oração subordinada adverbial causal reduzida de infinitivo que explica a fome no "restante do país" - que não a "Amazônia e largos trechos do litoral setentrional e oriental" e o "sertão semi-árido". Esta oração é "por adotar regimes alimentares inadequados". Ao mesmo tempo que, na EB, se produz o efeito de que uma suposta má escolha de 
alimentos em todo o Brasil não amazônico, não litorâneo e não sertanejo provoca a subnutrição, silencia-se a causa da fome nas outras regiões. A fome é significada como efeito de patologia biológica, sem relação alguma com a desigualdade social. No caso da Amazônia, endemia; do sertão semiárido, epidemia; do restante do Brasil, uma desnutrição provocada pela adoção de "regimes alimentares inadequados". O efeito produzido é que o brasileiro não tem conhecimentos suficientes para escolher seus alimentos. O atravessamento de uma ideologia do déficit (Mariani, 2004), de um discurso que põe o brasileiro como aquele que não sabe. É muito relevante que a única oração subordinada adverbial causal que indique motivos para a fome no Brasil responsabilize o brasileiro por uma formação de ementário alimentar débil.

Já na $E M$, que promove esse efeito de uma leitura voltada às mulheres, nas sequências que recortamos, o item "regime" é recorrente ao longo dos artigos sobre alimentos, comidas e receitas que se relacionam à imagem que se materializa discursivamente de Brasil. E o substantivo, que poderia vir acompanhado de qualificativos em expressões como "regime de saúde", "regime de qualidade de vida", "regime de engorda", repete-se, todas as quatro vezes em que ocorre, da locução adjetiva "de emagrecimento", tanto para alimentos recomendáveis quando para condenáveis:

$E M_{7}$ [extrato]: Fígado-[...] Pobre em gordura, é indicado nos regimes de emagrecimento. Fácil de ser digerido, pode ser dado a crianças e pessoas de aparelho digestivo delicado. Graças ao seu elevado teor de ferro, recomenda-se nos casos de anemias, para convalescentes, gestantes e lactantes.

$E M_{12}$ [extrato]: A LINCÜIÇA [...] Devido ao seu alto teor de gordura, a lingüiça é desaconselhável para pessoas que estão fazendo regime de emagrecimento; para reduzir a quantidade de gordura, ela pode ser cozida em grelhas.

$\mathrm{EM}_{19}$ [extrato]: [...] Abacaxi-É rico em vitamina C, contém pouco açúcar e tem baixo teor de calorias (cerca de 29 em cada 100g). Ao natural, é recomendado para quem está em regime de emagrecimento. [...]

Pinha - Sob o ponto de vista nutritivo oferece alto teor de açúcares de fácil assimilação pelo organismo. Esses açúcares enquadram a pinha (ao lado da banana, do caqui e da ameixa) entre as frutas pouco recomendadas aos que fazem regime de emagrecimento. ${ }^{18}$

Conforme significados na EM, figado e abacaxi são alimentos indicados/recomendados para quem está em "regime de emagrecimento", enquanto linguiça e pinha são desaconselháveis/pouco recomendados. O efeito de sentido produzido é de que o aconselhamento ou não dessas comidas para a mulher se dá por sua quantidade de gordura e de açúcar, o que se pode ver pelas justificativas da enciclopédia: "pobre em gordura" significa positivamente para o corpo; "Devido ao seu alto teor de gordura", negativamente; "contém pouco açúcar e tem baixo teor de calorias", positivamente; "oferece alto teor de açúcar", negativamente. Ao se fornecer sentidos dos atributos nutricionais dos alimentos dessa maneira, também se significam as práticas de alimentação da mulher e seu corpo: embora nas sequências não se especifique o gênero do sujeito de quem está em regime de emagrecimento - "indicado nos regimes de emagrecimento", "pessoas que estão fazendo", "quem 
está em" e "aos que fazem" -, o leitor inscrito na enciclopédia é a mulher, e é a ela que se dirige quando se produzem esses efeitos de sentido de que certas comidas atrapal ham o emagrecimento. No entanto, apesar de desrecomendadas por seu alto teor de gordura, as linguiças, para a $E M$, não escapam àquilo que o sujeito mulher deve saber cozinhar:

$E M_{12}$ [extrato]: São muitas as formas de preparo, sendo a mais comum a lingüiça cozida em água. Mas ela também pode ser grelhada, frita ou assada. Para fritar, coloca-se numa panela ou frigideira com pouco óleo e fogo baixo, sem espetá-la: dessa maneira, ela fica mais suculenta e gordurosa. Para fazê-la mais seca, coloca-se numa panela sem óleo e espeta-se para que a lingüiça frite em sua própria gordura. ${ }^{19}$

A enumeração de algumas maneiras de preparar a linguiça, entre elas a frita, com acréscimo de óleo além daquele já incluído no embutido, está presente na EM. Mesmo desrecomendando a linguiça para regimes de emagrecimento, a enciclopédia ensina esses preparos. Pressupõe-se que é necessário que se saiba preparar linguiças, mesmo que isso ameace o desejável corpo magro: a posição discursiva da dietética se põe em confronto com a posição discursiva da culinária, disputando sentidos pela linguiça, cujo tipo "caipira" é considerado "bem brasileiro".

$\mathrm{Na} \mathrm{EB}_{6}$, abaixo, inscrevem-se os sentidos sobre o corpo da mulher novamente numa FD médica afetada por uma FD sexista: repete-se que a mulher precisa comer menos do que o homem, ingerindo menos calorias, gorduras e açúcares por dia. Na EM, o corpo do sujeito homem é significado no silêncio, e a imagem do corpo do sujeito mulher é dito na pressuposição de quem deve se submeter aos regimes de emagrecimento. Abaixo, podemos observar como se produzem sentidos de padronização sobre corpos de homens e de mulheres:

EB $_{6}$ : ALIMENTO. [...] Calcula-se que um homem de 25 anos de idade, pêso e estatura médios, precisa de $3.200 \mathrm{cal}$. por dia e uma mulher, nas mesmas condições, de $2.300 \mathrm{cal}$., dependendo de seu trabal ho e do clima em que vivem. ${ }^{20}$

Entra em jogo aqui a memória discursiva de que homens são maiores do que mulheres, de que precisam ingerir mais calorias, de que seus dias envolvem mais trabalhos braçais: justificativas postas como naturais e culturais ao maior consumo calórico pelos homens e legitimadas por um discurso pautado no biologismo da posição discursiva da dietética e na ilusão de estabilidade e exatidão dos números da posição discursiva matemática, da FD ciências exatas: "25 anos de idade, pêso e estatura médios [...] 3.200 cal. [...] nas mesmas condições [...] 2.300 cal... ${ }^{21}$ A opção lexical por termos como "médios" e "nas mesmas condições" apaga o valor numérico que preencheria o peso

\footnotetext{
$19 \quad E M, 1976[1973] ;$ sublinha nossa.

$20 \quad E B, 1964$, p. 270; sublinhas nossas

21 Não sendo foco de nossa análise, ainda assim é notória a grande mudança desse padrão de ingestão calórica da década de 1970 para os anos 2000 e 2010. Se, antes, homens com essas características apontadas na sequência deviam consumir 3.200 calorias e mulheres 2.300 , contemporaneamente o recomendado por médicos e nutricionistas é que sujeitos homens consumam 2.500 calorias e que sujeitos mulheres consumam 2.000. Ambos os números diminuíram, mas para os homens a proporção de diminuição foi maior.
} 
e a estatura desses sujeitos e (o) briga o leitor a um conhecimento prévio e um reconhecimento da normalidade dos corpos de homem e de mulher, sem espaço para variação. Algo deve ser já sabido para a produção de sentidos.

A única relativização de ingestão calórica seria a variação de "trabalho e do clima em que vivem" esses homens e mulheres: e essa relativização produz imagens de trabalho e de clima normais, que contribuam para um consumo normal de calorias. Na FD médica, posição dietética, é possível, e sempre mandatório, que se diga de uma mulher idealmente magra e de um homem que possa comer (e beber) mais do que ela. Tudo sendo significado na ordem do óbvio e da evidência de que mulheres devem consumir menos calorias.

A EM também promove efeitos de sentido de que a mulher deve conhecer os detalhes nutricionais e dietéticos dos alimentos, e inclui numerosas informações sobre a quantidade de nutrientes dos gêneros alimentícios discursivizados.

A posição discursiva dietética engloba algumas das definições de "alimento" na EB:

EB : ALIMENTO. [...] As substâncias alimentícias são classificadas, quanto à composição química, em proteínas (substâncias plásticas formadoras), hidrocarbonatos e gorduras (substâncias energéticas), sais minerais e vitaminas (substâncias protetoras). (1964, p. 270)

$\mathrm{EB}_{8}$ : ALIMENTO. [...] Gorduras. [...] Entre elas figuram os azeites, gorduras neutras, as substâncias lipóides encontradas, p. ex., na nata batida, na gordura de porco, de vaca e de outros animais. ${ }^{22}$

A terminologia adotada pelo discurso médico é reproduzida na $E B$, enquanto que na $E M$ a posição dietética também significa e impõe como os artigos podem e devem ser escritos, mas através de um discurso de controle da alimentação a fim de um corpo mais magro, como temos visto. Dois modos de determinação discursiva pela FD médica, em sua posição dietética e da nutrologia.

Termos da biologia também surgem na EM, principalmente sob o intertítulo "Valor nutritivo" presente em alguns artigos, mas numa ordem invertida em relação à encontrada na $E B$ : notemos que, na $\mathrm{EB}_{8}$, diz-se das "Corduras" para depois se falar dos exemplos em que essas substâncias são encontradas - com exemplos de gêneros alimentícios europeus naturalizados pelo discurso enciclopédico, como a nata batida, a gordura de porco e a gordura de vaca. Já na EM, diz-se dos alimentos para depois se descreverem suas características nutricionais:

$\mathrm{EM}_{3}$ [extrato]: FEI]ÃO, UMA COMIDA BEM BRASILEIRA [...] Ele contém proteínas, sais minerais e vitaminas do complexo $B$.

EM ${ }_{7}$ [extrato]: A IMPORTÂNCIA DOS MIÚDOS E DAS VÍSCERAS [...] Cada $100 \mathrm{~g}$ de miúdos ou vísceras oferecem, em média, $20 \mathrm{~g}$ de proteínas, o que é muito significativo, especialmente levando-se em consideração que um adulto de 70kg necessita mais ou menos de $70 \mathrm{~g}$ de proteínas diárias. 
$\mathrm{EM}_{11}$ [extrato]: O COCO REALÇA O SABOR DOS ALIMENTOS [...] VALOR NUTRITIVO § O valor nutritivo do coco varia conforme seu estado de maturação. Mas, de uma maneira geral, pode-se dizer que apresenta um teor relativamente bom de sais minerais, proteínas, potássio, sódio, cloro e glicose, fáceis de serem assimilados pelo organismo.

$\mathrm{EM}_{12}$ [extrato]: A LINGÜIÇA [...] VALOR NUTRITIVO $\S$ Além de proteínas, a lingüiça contém ainda vitamina $A, B 1, B 2$, niacina e sais minerais como cálcio, fósforo e ferro.

EM $_{14}$ [extrato]:MARACU]Á, UMAFRUTA BEMBRASILEIRA§ Essa fruta contém carboidratos de fácil assimilação, fornece cerca de 90 calorias por $100 \mathrm{~g}$ e pequenas quantidades de sais minerais - cálcio, fósforo e ferro, além de vitaminas A e do complexo B. ${ }^{23}$

Os processos discursivos que funcionam na $E B$ e na $E M$ se inscrevem em posições discursivas que se tocam, mas a forma como eles se materializam é marcadamente atravessada pela imagem que se faz de seus sujeitos leitores. No entanto, ambas se inscrevem num discurso dietético, que, nas duas enciclopédias, vai fornecendo à comida contornos de substância bioquímica que deve ser incorporada por um sujeito significado como biológico. Além disso, e talvez principalmente, nesse embate que estamos fazendo entre $E B$ e $E M$, essa posição diz de uma divisão dos indivíduos em gêneros.

\section{Um sujeito universal... desde que europeu}

Na EB também se apresenta um programa de alimentação diário, em que se recomenda uma sequência de alimentos que "satisfaz as necessidades do organismo":

\footnotetext{
$E_{10}:$ ALIMENTO. [...] Regime que Satisfaz as Necessidades do Organismo. As necessidades do organismo de um jovem em período de crescimento e atividade podem ser satisfeitas com um regime de alimentos variados, como o seguinte: leite - de meio a um litro diário; hortaliças - três ou quatro rações diárias, que incluam batata, tomate, verduras cozidas e verduras cruas; frutas - duas ou mais por dia; ovos, carne ou peixe - um ou dois ovos por dia e uma porção de carne ou de peixe; pão e cereais - em cada refeição, pão de farinha de trigo integral; cereais - uma vez por dia. ${ }^{24}$
}

Para além dos itens lexicais extraídos da posição dietética, a Barsa enumera exemplos daquilo que deveria ser comido ao longo do dia para um regime que supra as "necessidades do organismo de um jovem em período de crescimento e atividade". Do ementário de alimentos constam batata, tomate, verduras, ovos, carne, peixe, pão e cereais. Alimentos que são discursivizados como de consumo universal, apagando as especificidades históricas, culturais, ideológicas de formações sociais específicas.

O incentivo ao consumo de leite é mais uma vez acentuado na enciclopédia: "de meio a um litro diário". Nas enciclopédias brasileiras, nenhum alimento é discursivizado de maneira tão unânime quanto o leite - e os laticínios -, respondendo como uma substância autônoma: enquanto frutas e hortaliças, por exemplo, funcionam como hiperônimos para gêneros em particular, o leite

\footnotetext{
$23 \quad E M, 1976-1973$; sublinhas nossas.

$24 E B, 1964$, p. 272; sublinhas nossas.
} 
parece dizer por si mesmo, e é sempre significado como indispensável, vital ao organismo. Apaga-se não apenas o já adoecimento dos indígenas ao consumirem leite, pela fal ta de lactase em circulação no organismo a partir do desmame, como também as diferentes espécies de mamíferos que podem produzir leite. O silêncio quanto a isso provoca o efeito de que são as vacas os animais que fornecem o alimento. Por consequência, nenhum lugar social é tão apagado no discurso enciclopédico sobre comida e alimentação quanto o do índio. Isso é repetido na $\mathrm{EB}_{9}$ :

$\mathrm{EB}_{g}$ : ALIMENTO. [...] Valôres de Certos Alimentos. O leite é um dos alimentos mais perfeitos. Pela elevada proporção de cálcio e fósforo que encerra, é superior a qualquer outro alimento na formação dos ossos e do tecido dentário. [...] A fruta crua é uma das melhores fontes de vitamina C, encontrada em proporção considerável na laranja, limão e outras frutas do gênero Citrus. Entre as hortaliças, as que contêm maiores quantidades de vitamina C são o agrião, a couve-flor, o aspargo, o espinafre, o nabo e o tomate. [...] § A carne de boi, as aves, o pescado ou produtos animais, tais como ovos e queijos, contêm proteínas. Os ovos constituem bom alimento, porque encerram substâncias lipóides, ferro e enxôfre, além de vitaminas. Como já ficou dito, as substâncias protéicas vegetais (ervilhas, feijão, soja, amendoim, lentilhas, grão-de-bico) não possuem tanto valor como as de origem animal, mas podem substituir a carne se o regime fôr complementado com leite ou com ovos. Apesar de sua riqueza em proteína, o regime à base de carne não deve ser exclusivo. O melhor é um regime misto de carne, leite, legumes, verduras e frutas. § Os cereais, tais como o trigo, o milho, a aveia e o arroz, contêm amido ou fécula que proporcionam energia e algumas proteínas. O grão e sua casca contêm minerais e vitaminas. Por isso, o pão feito de farinha de trigo integral ou os cereais complementados com ferro e outros sais e vitaminas são excelentes alimentos. Os doces, como o açúcar, o mel, as geléias e compotas são também alimentos energéticos, mas não devem ser administrados com exclusividade ou em proporções excessivas. ${ }^{25}$

Junto ao leite como alimento positivo para o sujeito - que recebe o predicativo "um dos alimentos mais perfeitos" -, comparecem os ovos. É dito que, unidos a grãos como "ervilhas, feijão, soja, amendoim, lentilhas, grão-de-bico", leite e ovos possibilitam a substituição da carne no regime. Pelos exemplos dados na $\mathrm{EB}_{9}$, subverbete "Valôres de Certos Alimentos", concluímos que a $E B$ se inscreve, além de tudo, num discurso internacionalista generalizante que, ao dizer da alimentação, apaga as especificidades do saber local: e acaba, num espaço restrito em que se trata de alimentos que são exemplos de nutrientes importantes na alimentação humana, evocando os aspargos, até hoje encontrados debilmente no território brasileiro, e a preços altos: o Cozinheiro nacional (2008 [circa 1870]) já dizia da dificuldade de se encontrarem aspargos no Brasil e se adianta, propondo substituí-lo por "brotos de samambaia, grelos de abóbora, palmito", assim como estimula o cozinheiro brasileiro a trocar nabos por "jerumbeba, quiabos, ora-pro-nóbis, lobolobo" (p. 35). Mais de um século depois da publicação do Cozinheiro nacional, o gesto de exemplificar alimentos ditos úteis no dia a dia é dominado por um discurso eurocêntrico em que leite, ovos e pão de farinha de trigo são algumas das comidas mais valorizadas. 
Retoma-se na $\mathrm{EB}_{9}$ também o já-dito em outras enciclopédias anteriores (Esteves, 2017) ao se considerar que "O melhor é um regime misto de carne, leite, legumes, verduras e frutas": um efeito de norma que não deixa espaço para aqueles que não podem ou optam por não tomar leite e para aqueles que preferem não ingerir carne, inscrevendo-se numa refeição recomendada no discurso europeu. $\mathrm{Na} \mathrm{EB}$, acumulam-se expressões que produzem efeitos de uma alimentação baseada na quantificação: "elevada proporção", "proporção considerável", "maiores quantidades", "tanto valor como", "proporcionam energia", "proporções excessivas". Algumas espécies nativas das Américas resistem nesse discurso da $E B$, como o feijão, o amendoim e o milho - o que demonstra haver uma transmissão de saberes dominados, subalternos, no discurso dominante, uma resistência do colonizado.

\section{Desfechos e promessas}

Neste artigo, procuramos trazer alguns dos principais aspectos que se apresentam na Enciclopédia Barsa e na Enciclopédia da mulher: as sequências discursivas marcadamente significadas por um discurso médico que acaba por evocar as diferenças entre corpos e gêneros, mas universalizando práticas alimentares como o consumo de leite. Vimos também que, ainda que se queiram como instrumentos que produzem sentidos sobre os brasileiros, essas enciclopédias resvalam em saberes eurocêntricos sobre o Brasil. Na EM, publicada para a mulher, extraímos também como saldo que é necessário que a mulher, mais do que o homem, cuide de seus regimes, considerando os menos calóricos preferenciais. Pouco dissemos, neste artigo, entretanto, sobre o imaginário de constituição da culinária nacional. Pretendemos apresentar esse aspecto igualmente interessante em futuras publicações, salientando, contudo, a importância de, ao se discutir comida, não se apagar gênero, corpo, nacionalidade e discursos dominantes. Comida, alimentação e política andam muito mais próximas do que se supõe.

\section{Referências}

ACUIAR, João Baptista da Costa. Senhor prendado: um homem que se diverte na cozinha. São Paulo: Leya, 2011.

ANDRADE, Mário de. A enciclopédia brasileira. Edição crítica e estudo de Flávia Camargo Toni. São Paulo: Giordano/Loyola/Edusp, 1993.

ARAÚJO, Maria Marta. Com quanto tolos se faz uma República? Belo Horizonte: EdUFMG, 2007.

CASTRO, Josué de. Geografia da fome. 10. ed. Rio de Janeiro: Antares, 1984 [1946].

COZINHEIRO nacional: ou Coleção das melhores receitas das cozinhas brasileira e europeias. 2. ed. Acompanhado das Regras de servir à mesa e de trinchar. Prefácio de Carlos Alberto Dória. São Paulo: Ateliê Editorial/ Editora Senac São Paulo, 2008 [circa 1870].

ESTEVES, Phellipe Marcel da Silva. Discurso sobre alimentação nas enciclopédias do Brasil: Império e Primeira República. Niterói: Eduff, 2017. 
MARIANI, Bethania Sampaio Corrêa. Colonização lingüística: línguas, política e religião no Brasil (séculos XVI a XVIII) e nos Estados Unidos da América (século XVIII). Campinas: Pontes, 2004. NUNES, José Horta. Para uma história do discurso enciclopédico no Brasil. Anais do XXVII Encontro Nacional da Anpoll, Niterói, UFF, 2012. Disponível em:<http://www.labeurb.unicamp. br/anpoll-2010-2012/resumos/josehorta.pdf>. Acesso em nov. 2018.

ORY, Pascal. O corpo ordinário. In: COURTINE, Jean-Jacques (Dir.). História do corpo: 3. As mutações do olhar. O século XX. Tradução e revisão: Ephraim Ferreira Alves. 3.ed. Petrópolis: Vozes, 2009 [2006]. PÊCHEUX, Michel. Análise Automática do Discurso (AAD-69). In: GADET, Françoise; HAK, Tony (Orgs.). Por uma análise automática do discurso. Campinas: Editora Unicamp, 1990 [1969]. Semântica e discurso: uma crítica à afirmação do óbvio. 4. ed. Tradução: Eni Orlandi et al. Campinas: Editora Unicamp, 2009 [1975].

PEREIRA, Mateus Henrique de Faria. A trajetória da Abril Cultural (1968-1982). Em Questão (UFRGS), Porto Alegre, v. 11, pp. 239-258, 2005.

TONI, Flávia Camargo. Introdução. In: ANDRADE, Mário de. A enciclopédia brasileira. Edição crítica e estudo de Flávia Camargo Toni. São Paulo: Giordano/Loyola/Edusp, 1993. 